\title{
DỨBin
}

Technological University Dublin ARROW@TU Dublin

\section{Ireland, Broadcasting and the Spectrum Wars}

\author{
Kenneth W Murphy \\ Technological University Dublin, kenneth.murphy@tudublin.ie
}

Follow this and additional works at: https://arrow.tudublin.ie/gradcamart

Part of the Broadcast and Video Studies Commons, and the Communication Technology and New Media Commons

\section{Recommended Citation}

Murphy, K. (2020) Ireland, Broadcasting and the Spectrum Wars, Journal of Digital Media \& Policy, Volume 11, Number 1, 1 March 2020, pp. 29-46(18) DOI: 10.1386/jdmp_00010_1

This Article is brought to you for free and open access by the Graduate School of Creative Arts and Media at ARROW@TU Dublin. It has been accepted for inclusion in Articles by an authorized administrator of ARROW@TU Dublin. For more information, please contact arrow.admin@tudublin.ie, aisling.coyne@tudublin.ie, gerard.connolly@tudublin.ie.

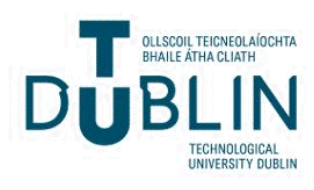




\section{DỨcin}

Technological University Dublin ARROW@TU Dublin

\section{Ireland, Broadcasting and the Spectrum Wars}

Kenneth W. Murphy

Follow this and additional works at: https://arrow.tudublin.ie/aaconmusart

Part of the Television Commons

This Article is brought to you for free and open access by the Conservatory of Music and Drama at ARROW@TU Dublin. It has been accepted for inclusion in Articles by an authorized administrator of ARROW@TU Dublin. For more information, please contact

arrow.admin@tudublin.ie, aisling.coyne@tudublin.ie. (c) (†)(2)

This work is licensed under a Creative Commons Attribution-Noncommercial-Share Alike 3.0 License

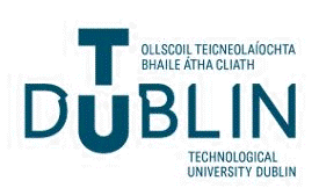




\title{
Ireland, Broadcasting and the Spectrum Wars \\ Kenneth Murphy, Technological University Dublin
}

\author{
Author: Murphy, Kenneth \\ Source: Journal of Digital Media \& Policy, Volume 11, Number 1, 1 March 2020, pp. 29-46(18) \\ Publisher: $\underline{\text { Intellect }}$

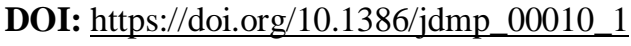

\begin{abstract}
This paper offers an overview and evaluation of Ireland's changing media landscape through the prism of the recent policy contestation surrounding the future use of the UHF spectrum and it's implications for the medium of television broadcasting. The article brings into focus current policy and governance developments and their interplay with market and technological change and how they are shaping a small open European state's adaptation to the increasingly complex national/global hybrid media ecosystem. It examines the contexts surrounding the competition for spectrum resources and its implications for the role of free to air broadcasting and mobile broadband technologies in the future delivery of media and communication services. It takes a political economy and institutionalist perspective to evaluate the extent to which the evolution of the Irish institutional framework regarding broadcasting and broadband development and the allocation of spectrum frequencies is shaped by broader political economic and political/institutional dynamics and what this means for broadcasting within the evolving digital media ecology.
\end{abstract}

Keywords: UHF Spectrum, Public Service Media, Policy, DTT, Broadcasting, Mobile Broadband.

\section{Context}

The recent debates and activities surrounding the use of the UHF spectrum at European and national level bring into sharp relief the tensions and dynamics underpinning the process of adaptation to technological and political economic change in electronic 
communications. As Cave and Webb have argued, 'territorial wars are seldom waged over infertile land', and this is the case when it comes to the UHF block of radio spectrum (Cave and Webb 2015). In Europe, the block was historically used for the broadcast distribution of free to air terrestrial television but is now also a crucial resource for mobile telecommunications industries that claim that they need access to spectrum to meet user demand for access to audiovisual services across their networks. This scenario has created intense competition for the spectrum resource, and western governments have moved from defining spectrum as a public good to a market-based system of spectrum auctions for resource allocation (Taylor 2013). Simpson and Humphrey's (2018) propose that the contestation around spectrum resources illustrate how media convergence via digitisation must negotiate the messy reality of interest contestation, the material and the institutional difference between different media and their uses and the tension between public service media and commercial media development. According to the authors;

Rather than spectrum illustrating a smooth path of convergence between broadcasting and mobile communication, the picture is one of perceived incursion on the one hand, and intransigence, on the other, leading to open, sustained policy contestation (Simpson and Humphreys 2018: 54).

The policy contestation around spectrum overlaps with a broader question regarding the socio-technological infrastructures of media and communication and how media reach the public. Infrastructures are the broad technical systems upon which multiple media services are circulated. As Taylor has succinctly stated, the emergence of wireless digital services means 'spectrum is an invisible public resource that is an increasingly essential component of the global digital media superstructure' (Taylor 2013). The development and diffusion of $5 \mathrm{G}$ networks further support this claim, placing spectrum at the centre of an infrastructure that 'will impact society in many ways' (EBU 2016). Both mobile phone and terrestrial broadcast use of spectrum to provide digital media and communications infrastructures are thus elements of an increasingly complex media/IT/Telecom ecosystem (Simon 2016). Broadcasters are 
developing new value chains and enter into relationships with multiple infrastructure providers to distribute linear and non-linear services, data services and live and ondemand services, increasingly mixing broadcast, narowcast and networked dynamics. Crucially 'distribution and the terms of access, to public service media content, has significant public interest implications' (Michalis 2017: 195). These relate to the autonomy, universality and access conditions of public service media. Thus, public service media organisations and their representative bodies have become more focused on their requirements for distribution (EBU 2017, BBC 2018). Universal and free at the point of access distribution sets an optimal baseline for the realisation of the social and democratic benefits of public media with broader consequences for the composition of the media system overall.

\section{Framework and methods}

The paper takes a political economy approach to evaluate the interplay of state, market and society in the allocation of communications resources and what this means for questions of the political and economic organisation of media in the contexts of complex ecosystems. It also draws upon new institutionalism to evaluate the role of existing and emerging formal and informal rules, relationships and organisations in the field of communications and how they shape decisions and outcomes in the media field. It consists of, based on document analysis, a case study of the policy and politics surrounding Ireland's second digital dividend and, based on elite interviews with a number of sources in broadcasting (media, policy and regulation), an evaluation of the place of free to air digital television in the evolving infrastructural framework.

The research directly addresses four research questions adapted from the author's involvement in a pan-European study (Broadcasting in the Post Broadcast Era). In the contexts of competing claims to spectrum resources for different communicative uses:

1. What does the contestation surrounding the UHF spectrum resource allocation reveal about the ideas, institutions and interests driving policy decisions around 
media infrastructure and what might that mean for the future of broadcast media?

2. To what extent, following the digital transition, does broadcasting as a medium remain important in Ireland's communications policy?

3. How important is terrestrial broadcast distribution for broader public policy goals in media, and how is this reflected in policy choices?

4. Could mobile broadband replace terrestrial broadcasting as a central policy objective and a potential platform for terrestrial broadcast services?

The paper aims to assess the hypothesis that, following the first digital dividend, due to the emphasis on distribution and broadband, broadcast media are de-emphasised in media/communications policy, and, resources (including spectrum) formerly accorded to broadcasting are being transferred to what are perceived as higher value services (Hujanen 2014).

\section{International Political Economic Contexts}

In 2007 the International Telecommunications Union's World Radio Conference (WRC) agreed, planned and coordinated the migration of broadcast television out of the $800 \mathrm{MHz}$ band leaving it open for repurposing. At this juncture, the European Commission had considerable influence on member states' policy at the WRC and was centrally concerned with regaining European leadership in the development of the mobile communications sector (Ala-Fossi and Bonet 2018). The characteristics of the UHF spectrum, the portion of spectrum primarily occupied by radio and television broadcasting, make it attractive to mobile phone operators. The use of lower frequency bandwidth (UHF) reduces the cost of wireless broadband services in rural areas, whereas the high-frequency spectrum allows more capacity in urban areas (Cave and Webb 2015). The 2007 WRC decided on the allocation of released spectrum to uses other than broadcasting, e.g. the mobile phone industry.

Following the first Digital Dividend, attention turned to the $700 \mathrm{Mhz}$ band and the remainder of the UHF spectrum. The WRC 2012 proposed the allocation of the UHF 
spectrum band (694-790MHz) to mobile as co-primary with broadcasting from 2015, ratified at WRC 2015. This move surprised the European broadcasting industry as it was initiated by the African and Asian states that had previously followed Europe's lead at the WRC (Ala-Fossi 2016). The WRC also placed the discussion of the allocation of the remaining (sub 700MHz) UHF spectrum on the agenda for 2015. Mobile phone companies and their representative bodies had exerted considerable pressure on African and Asian national governments to pursue this policy direction. The proposed discussion prompted intense lobbying on behalf of the Broadcast industry within Europe, and the Commission was forced to respond and co-coordinate its member states position on spectrum management in the UHF band.

The Commission published the Lamy Report in Sept 2014 recommending 'the $700 \mathrm{MHz}$ band (694-790) should be re-purposed for wireless broadband, regulatory stability should be ensured for broadcasting to continue its current use of the band 470$694 \mathrm{MHz}$ until 2030 and a stock-taking exercise of UHF spectrum use should be performed by 2025' (Lamy 2014). The Commission adopted this position which was copperfastened by European Parliament consensus in 2017. Ireland supported this position at the WRC 2015. The current case study traces the inflexion of these developments in Ireland from 2012 until 2017 when the government designated the $700 \mathrm{Mhz}$ band for clearance.

\section{Broadcasting and Mobile Broadband in Ireland}

Macroeconomic policy drives Ireland's integration into global markets and value chains and has consequences for media and communications policies. A political consensus around foreign direct investment, competitiveness and economic growth legitimize a policy mix (liberalization, privatization, corporatization and re-regulation) that supports global corporate investment in the generation of digital media networks and markets. Increasingly, market logics are integrated with socio-political and sociocultural logics in policy frameworks. Arguably, market centric digitalization has provided both material and ideational justification for a reduced institutionalization of 
public purposes in media and communications (and across society in general) (Fischer 2010).

Digital television policy was developed within an overall framework of liberalization, presumed convergence (de-regulation) and market development (re-regulation). The telecommunications regulator, Comreg, following the European Commission's lead, was tasked with its introduction. Comreg focused on the deployment of competitive platforms, broadband roll out and the generation of new communications markets following analogue switch off. One of the key policy goals behind state support for DTT was the release of spectrum for new mobile communication services (4G) while supporting the national free to air broadcasting system. Switch-off created the contexts for a digital dividend through spectrum release in the $800 \mathrm{Mhz}$ band.

The early development of DTT was, however, hampered by the state/government's favouring of market mechanisms and solutions in policy directed towards institutionalising digital media markets allowing Satellite and Cable to establish first mover advantage. The proposed DTT platform suffered from long periods of policy contestation resulting from marketisation and a lack of state intervention. This diminished its incumbent status and dis-incentivised commercial investment in the platform. Thus a wholly owned subsidiary of public broadcaster RTE, 2RN, was left with the full policy burden to launch, fund and maintain Saorview. It currently provides two free to air multiplexes for RTE, TG4 and Virgin Media's terrestrial channels. As a secondary service it is the television platform in the highest percentage of households in the Irish Republic, 42 per cent, but is the primary service for just 11.5 per cent of households (Comreg 2018).

Policy towards the digital transition accelerated the integration of Irish communications services and infrastructures into the global value chains and networks of global media corporations. Virgin Cable (owned by the US-based Liberty Global) and BSkyB (owned by the US-based Comcast) (satellite platform) are the two most widely diffused (pay) digital television platforms (65 per cent) also offering triple play 
services. As is the case in other technologically advanced states, internet/broadband enabled OTT (US-based Netflix) and platform based viewing (the US owned Facebook, Google, Apple, Amazon), along with other media practices, are eroding audiences for linear content but not wholly replacing them. However, alongside nonsubscription free to air satellite and use of off-air UK DTT, 'recent trends demonstrate growth in the popularity of free TV options at the expense of pay TV' (Mediatique 2017). Both linear radio and television media remain strong in the digital environment with live/linear radio and television accounting for the most time spent with audio and video media, respectively (Mediatique 2017).

The mobile industry, with its attendant broadband offerings, has significant strategic value for the State while spectrum auctions result in windfall yields also promising ongoing spectrum fees. Three global mobile phone companies successfully bid in an open auction for spectrum in the $800 \mathrm{Mhz}$ band. Eir (Owned by French-based Illiad), o2 and Vodafone (Owned by UK based Vodafone) collectively paid 482 million in upfront fees. A further 373 million will be paid between 2013 and 2030 in continuous spectrum user fees. Each of the companies, in their bids, proposed to use the additional spectrum to roll out 4G/LTE services. In 2013 Hutchison 3G Ireland (Hong Kong based CK Hutchison) acquired 02 ensuring consolidation in the mobile market. The auctions signalled the growing importance of the terrestrial spectrum in Ireland's economic and social development and its contribution to the health of the public finances in the wake of the global financial crisis. It also highlighted the expansion plans of global mobile operators and the overlap of these with television.

In the contexts of marketization, digitization and convergence a new competitive ecosystem has emerged wherein telecom and content companies, compete in multiple overlapping markets and vie 'to own the home'. Internet-based companies such as Apple, Amazon, Google and Netflix also attempt to dominate the media ecosystem through shifting power downstream via over the top integration of content, hardware and software. In 2015/2016 Virgin cable bought out two commercial television channels (TV3 and UTV Ireland) to compete in the television content market whereas 
Sky provides a popular suite of UK based channels with 'opt out' Irish advertising. Eir, which launched its television service e-vision in 2013, redoubled its interests in the channel's market in 2016 with the buy out of sports channel Setanta. Vodafone, since 2016, offers an IPTV based television service. Sky, Virgin, Eir and Vodafone all offer multichannel, mobile telephony and broadband services, with Eir, Vodafone and 3 also offering mobile broadband. In these contexts, many of these companies compete for spectrum as infrastructure; all offer audiovisual services, whereas the OTT/platform services, directly and indirectly, benefit from ubiquitous broadband. As commercial media/communications industries they all strive to reduce risk and increase revenues. Control of distribution and gateways enable multiple strategies to achieve those goals (Hesmondhalgh 2012). Channel bundling, algorithmic control, epg's, datafication, content platforms and distribution platform development are all aspects of these strategies. The rationale and justification for de-commodified and universally accessible public goods and infrastructure, as an object of policy, remain strong.

\section{Spectrum Policy in Ireland}

Given the lack of pressure on spectrum use in Ireland and its public good character previous to liberalization in the 1990s, there was, up until 2010, no explicit government policy framework on spectrum. The Department of Communications (and its antecedents) coordinated spectrum use, but in tangent with EU policy, a switch to market centred policies in the 1990s entailed the development of a new institutional framework. The 1996 Telecommunications Act created the ODTR (later Comreg) as the National Regulatory Authority for Telecommunications and required it to provide a frequency plan for the spectrum and license the use of wireless telegraphy equipment. Comreg was given the responsibility to oversee the efficient use and effective management of the radio spectrum. It works with the BAI (Broadcasting Regulator) in granting broadcasting licenses for analogue and digital broadcasting and the licensing of multiplex services.

In 2002 the Department of Communications, Marine and Natural Resources was created as the lead Department for both broadcasting and telecommunications 
developments. The publication in 2010 of a statement on 'Spectrum Policy Objectives and Principles' provided a general framework for spectrum management. Government would ensure that the national spectrum resource is managed and used effectively and efficiently so that Ireland remains competitive on a global basis. The Department/Minister thus has primacy in overall policy direction. It also stated the importance of spectrum in contributing to the quality of life of citizens. Rhetorically it gives equal weight to spectrum management that serves public service and competitive objectives.

Spectrum is also an element of Ireland's successive National Broadband plans. As it positions itself as a hub for the global technology sector, ubiquitous high-speed broadband is a crucial infrastructure for the Irish state and has been driven by foreign direct investment with public investment supplementing market failure. Despite multiple public investments, there are still 'broadband blackspots' in rural areas. The UHF spectrum is suited to cost-effective rural wireless broadband provision. Currently, the most recent National Broadband Plan (2016) has set its focus on fibre, but development and diffusion of $5 \mathrm{G}$ and it's spectrum needs make it probable that future governments will consider the UHF spectrum as part of a potential future solution for finalizing universal broadband infrastructure.

\section{The Skirmish for UHF Spectrum in Ireland}

Even before the 2012 spectrum award (the first digital dividend) was finalised, Comreg anticipated further demand for spectrum in the contexts of the rapid growth of smartphones in the mobile phone market. In 2011 it detailed the importance of mobile telephony in extending broadband access, the increased use of data by mobile phones and the contribution of spectrum to the Irish economy (then estimated at $2.2 \%$ of GDP) (Comreg 2011). It speculated that the 700Mhz band may emerge as the likely second digital dividend but did not see this as imminent (given the status of decision-making in CEPT and the EC). Comreg was overtaken by developments at the WRC 2012 with the push to allocate the UHF spectrum band $(694-790 \mathrm{MHz})$ to mobile as co-primary with broadcasting from 2015. 
The reactions to these developments from broadcasters and broadcast network providers at European level had an inflexion at the national level. In 2013 the Department of Communications facilitated the formation of the UHF spectrum group, consisting of representatives from the terrestrial broadcasters (RTE, TG4, TV3) the network operator (2RN), the regulator (BAI) and the Department of Communications (Broadcast Division). The purpose of the group was outlined as 'examining the current issues and expected future developments associated with the current use of UHF spectrum for purposes of 'free to air' DTT broadcasting and establishing a defined policy in regard to the continued use of such spectrum for these purposes' (DCENR (a), 2014). Ultimately the group aimed to justify the remaining UHF spectrum resources available for television broadcasting and produced a report in 2014 to do so.

Notwithstanding developments in international policy and the increased influence of the mobile phone industry at Global and European level, the national broadcast policy stakeholders faced local issues. In 2013 the BAI had commissioned and published a report evaluating the prospects for commercial multiplexes on DTT. The report concluded that due to changes in the television market and the general economic environment, the outlook for private investment in commercial DTT multiplexes was now unlikely. It noted the diminished market for DTT and the increased dominance of cable and satellite platforms. It also argued that technological capacity and bundled offerings were rendering the DTT option less attractive.

DTT also has limitations compared with competing distribution platforms: It is an expensive means of transmission compared with digital satellite, and does not have the functionality such as on-demand TV, telephony and internet access which digital cable offers (Oliver and Ohlbaum 2013).

It proposed that 'the future of Saorview as a high reach service is not assured unless the content and functionality available on the platform continues to develop. Without a wider offering, we believe that Saorview will continue to decline in popularity and will 
reach a point sometime after 2020 at which its economics become questionable'. In the contexts of developments at the ITU and the pending consultations on the future use of spectrum in Ireland, from the perspective of the broadcast stakeholders, this was not a welcome intervention. Following the report, the BAI issued a statement acknowledging that the development of commercial DTT was now inadvisable.

In February 2014, Comreg issued a consultation on management and use of the UHF spectrum in Ireland (Comreg 2014). The latter move surprised the broadcasting policy community and pre-empted the outcome of discussion scheduled for item 1.1 of the WRC 2015. The document argued that a national position on the UHF band was necessary. The consultation specifically addressed Ireland's potential position concerning the subsequent designation of the $700 \mathrm{MHz}$ band at the $\mathrm{WRC}$ as co-primary and the anticipated discussion surrounding the future uses of $470-700 \mathrm{MHz}$.

Comreg's consultation document cited the Oliver and Ohlbaum report on the prospects of the commercial DTT multiplex. It pointed to the unlikely investment into commercial DTT (4 national multiplexes), the BAI's response and the fact that this would lead to the under utilisation of spectrum earmarked for DTT in the UHF band. It presented graphically the amount of spectrum allocated to DTT in contrast with that used. It calculated that the use of two multiplexes by the Saorview platform left seven unused. The document proposed that in European terms Ireland was, closer to those countries who had no plans for expansion of DTT (Germany and the Netherlands). The spare capacity of DTT, it argued, could be reused to deliver the Saorview services via LTE over mobile networks to mobile phones. It appeared that Comreg, having released spectrum in 2012 to companies investing in $4 \mathrm{~g} / \mathrm{LTE}$, was specifically promoting the further support of the technology and the mobile operators through increased access to spectrum and broadcast content.

The UHF policy group offered a balance to some of the claims made in the Oliver and Olbaum report and restated by Comreg. It traced the connection between national broadcasting policy, terrestrial television policy and the development of DTT. It 
highlighted the continued importance of linear live free to air television for both policy, broadcasters and citizens and highlighted some of the questionable statistics that heralded a data crunch for mobile broadband that had been accepted, seemingly uncritically, by Comreg. It also outlined the technological limitations of the competing communication networks and distribution systems (Mobile TV, Satellite, Cable, Fixed Broadband, WiFi) in replicating the reach, capacity, cost and efficiency of D.T.T. as well the issues relating to ownership and control of proprietary distribution platforms. The report, in conclusion, recommended that the primary allocation of UHF spectrum for broadcast purposes be maintained for the continued provision and development of a national free-to-air DTT network and ancillary services until at least 2025. It pointed to the future development of the platform (HDTV services and ultimately UHDTV) and the popularity of the service.

Comreg's pre-emption of discussion on the sub 700 UHF spectrum took the Department of Communications by surprise and appeared to overstep the boundary in terms of Comreg's responsibilities on policy. The Department stepped in with a consultation four months later, and Comreg's plan to follow up its preliminary consultation with a full consultation on spectrum management in the UHF band was never realised. The government and Department were involved in the European debates surrounding a common European position on the UHF band. By September 2014, the Lamy report followed the formula of allowing co-use of the 700Mhz band but restriction of the rest of the UHF band to broadcasting until 2030. In parallel, at the international level, two groups, the ECC TG6 and the EC High-Level Group on Future Use of UHF Spectrum, were established to consider the future of the entire UHF broadcast band (470-790 MHz).

ComReg's published response to its initial consultation sounded a conciliatory note concerning it's perceived overstepping of boundaries. In the introduction, it acknowledged:

While there has, in recent years, been a rapid growth in demand for mobile 
broadband services, there is also an established and continuing strong demand for a high quality, free-to-air national terrestrial television service. Many Irish users want fast internet access on their smartphones and tablets but many also want to watch television, including programmes which reflect local culture and values. An optimal solution, in terms of spectrum management, would allow them to do both (Comreg 2014).

The skirmish over the UHF spectrum demonstrated the strong institutional pull of Comreg towards the European agenda for network development, broadband rollout and the forces and pressures of dealing with powerful global stakeholders in a hypercompetitive communications environment. Briefly, Comreg had aligned itself with the policy goals of mobile broadband firms advancing their agenda through African and Asian states at the WRC. The formation of the UHF group and the role of the Department of Communications in tempering the perceived incursion of Comreg and the mobile operators into issues of broader media and communications policy illustrate the reactive nature of support for free to air television and public service media at the level of state if not government. Broader contexts, however, also mattered. The Department's move partly reflected pressure from the broadcast field but also reflected the decision taken by the Commission (on the 700Mhz spectrum) and the necessity of Ireland co-coordinating its allocation of spectrum with the UK. What the skirmish highlighted was the vacuum left by the commercial DTT model and the void in forward-looking state support for domestic broadcasting initiatives that might expand the free to air ecology. Such a vacuum leaves the platform vulnerable to resource grabs, now and in the future.

The responses to the Department's consultation on the possible future uses of the sub $700 \mathrm{MHz}$ frequencies offered a clear articulation from the primary providers of mobile phone and broadband services (Three, Vodafone and Eir) that the frequencies be considered for re-purposing to mobile. In their submissions RTE and civil society group Ireland Offline supported the continued priority given to broadcasting in the UHF band. The responses illustrate the developing balance of interests in the Irish 
communications sector and their overlap concerning markets and resources. For the mobile network and broadband operators, there is significant interest in the unused spectrum of DTT. For triple and quad players there is considerable interest in DTT not being a viable free to air competitor in television markets.

Following a cost-benefit analysis in 2017, the Department proposed that the 700-790 $\mathrm{MHz}$ spectrum would be repurposed and auctioned by Comreg for mobile communication use in 2020 (in coordination with the UK). In total, since the first digital dividend and with the completion of the second digital dividend auctions, Television Broadcasting will have lost $100 \mathrm{MHz}$ of spectrum, roughly 33\% of its pre liberalisation allocation.

What is clear from the case study is the absence of mechanisms and capacity for adjudging values other than economic values in decision-making about the use of public communication resources. For Comreg, broadcasting does not generate windfall sales and ongoing user fees, or facilitate broadband, and thus, within Comreg's market based institutional framework, is a less efficient use of spectrum. Cost-benefit analyses and consultations lack any means of weighing up the social, democratic and cultural value of media services and the infrastructure they depend upon and rarely open up these important questions, beyond industrial stakeholders, to the public. Focusing on economic value and user behaviour, important as they are, negates any systematic consideration of socially optimal outcomes in the use of public resources. Also absent is a regulatory space to consider recombinant value chains and distribution/gatekeeping power as an object of eco-systemic regulatory intervention and management.

Subsequent developments provide good reason to consider the broader implications of this battle for spectrum and it's potential consequences for broadcasting, public media and public resources in the Irish adaptation to global infrastructural change. A 2017 report by Mediatique attested to the resilience of free to air DTT in the broadcasting space reporting that 'the appeal of DTT is arguably greater (from this improved counterfactual) than predicted in Oliver \& Olbauhm's analysis' (Mediatique 2017). 
Added to this, global trends of so-called 'cord cutting' in favour of combining free to air television with online subscriptions have illustrated that terrestrial broadcast is a resilient complementary distribution platform. And presently, the development and diffusion of $5 \mathrm{G}$ technologies potentially offer a pathway for the utilization of spectrum for the straight to mobile/smartphone delivery of linear and non-linear media services (EBU 2016). This, if politically supported, could potentially extend the free to air infrastructure and the cultural value of broadcast media and new digital genres, forms and content (cross-media, interactive content, augmented reality, virtual reality) to the younger demographics who increasingly access audiovisual content on handheld devices rather than traditional television devices. With enough policy support (and courage), a renewed institutional framework for public service and public interest media could also be extended in the $5 \mathrm{G}$ environment.

Contestation of spectrum use is a pertinent example of the need to anticipate future public purposes in media that are in danger of being closed off in the contexts of marketisation. It also necessitates joined up and multi-level thinking concerning issues of overlapping and contested value chains. There is a mounting public interest opportunity for DTT providers, to use their allocated public spectrum resources and broadcast infrastructure, to provide universal $5 \mathrm{G}$ enabled linear/networked services free at the point of access. The institutional framework for content/service could also specify the public service/public interest needs of universal access and free of recurrent charge services and develop protections against blocking, filtering or gatekeeping by non-broadcast 5G providers (e.g. mobile phone companies) (EBU 2017). Public Service media would also thus retain control over their channels of communication and access customer data as a public resource, an increasing concern in the contexts of platformisation and monetisation of television delivery.

\section{Policy and resource distribution in the developing infrastructural framework}

In the course of research for a trans-European project, the issue of spectrum allocation and the development of communications policy in Ireland was explored in elite interviews with ten senior policy stakeholders ${ }^{\mathrm{i}}$. The overall picture that emerged from 
these interviews was the recognition that the telecommunications agenda and related digital and broadband agenda is (perhaps rightly) dominant in the Irish political context and consideration of terrestrial broadcasting, public service values and the place of the domestic broadcasting content sector is overshadowed but not eclipsed by the dominance of this agenda. The evolving challenges of digitisation, convergence and network proliferation for nationally based public interest broadcast media have, however, been met with wavering political attention and the continuation of historically underwhelming public investment and political support to sustain a still relevant (in political, economic, cultural and social terms) medium (broadcasting) and its continued evolution in a digital and networked ecosystem. The reaction to the developments surrounding the UHF spectrum demonstrate a scenario whereby the failure to allocate political and economic capital to free to air broadcasting's digital evolution, it's effective under-resourcing, opens the door to resource grabs. Such governmental inattention may undermine the normative conditions of autonomy, universality and accessibility for broadcast based digital media services, if not now, then in the future.

\section{Broadcasting and National Policy}

All respondents agreed that broadcasting would remain relevant as a medium in Ireland and it's media policy up to 2020 and beyond. The broadcast regulator (BAI Respondent) explains this importance in terms of facilitating freedom of expression, national public debate and cultural expression.

The respondents pointed to evidence that other policy agendas are replacing the centrality of terrestrial broadcasting within media/communications policy and that this, combined with the future economic viability of broadcasting itself, is problematic. According to the Civil servants in the Department, broadcasters face the dual challenge of adjusting to new modes of delivery and consumption that are also 'difficult for them to monetise' (Dept of Communications Respondent 2016). The respondent from the quad play telecommunications/media company Eir, echoed this and also pointed to the future viability of the national broadcasting ecosystem. 
In a global environment where consolidation and mega-media empires are becoming the norm, the long-term sustainability of small-scale broadcasters in markets that are challenged in terms of scale is a real issue (Eir Respondent 2016).

The respondents point to the still strong demand for broadcast media across multiple hybrid platforms. The Dept of Communications respondent proposed that Irish television stations still retain a majority of viewing share across the various platforms (satellite, cable and fixed-line telecommunications) but policy will need to continue to support that position 'from a democratic point of view'.

All of the respondents see increased challenges for terrestrial broadcasting in terms of resource allocation, policy choices, technological change, market competition and user behaviour. All of the respondents suggest the successive failure of governments to address the comparatively low level of the license fee, its collection method and its form has reached a critical stage. The issues of opt-out advertising removing money from the Irish market, the migration of advertising to online platforms and the inability of broadcasters to charge retransmission fees (on cable and satellite) are also mentioned.

For the most part, the interviewees accepted that broadband deployment is a priority government policy endeavour and suggest that broadcasting retains support, but there is overall a decline in the power and resources dedicated to broadcasting issues. The need for balancing objectives around competing claims to policy resources is central. According to the BAI respondent, the relationship between investment in broadband and media content are all issues that should be considered in 'the same space in terms of balancing objectives' (BAI Respondent 2016). The issues arise at an ecosystemic level (across production, distribution and consumption) but, as the case study above illustrates, policy is not matched to this dynamic. 
The RTE Respondent pointed to the current policy emphasis on distribution to the cost of policy concerns surrounding content;

Much of the focus of the various digital strategies, national digital strategies have all been, and probably rightly, about A) access, to begin with, coverage of rural broadband, so B) getting businesses online so they can trade and create jobs etc. which ... was probably the right focus. But longer term I do think there needs to be a much broader discussion about what people are consuming, why they're consuming it, how they're consuming it, who's making it, how can we trust it, I mean there are much broader questions around the value of media generally (RTE Respondent 2016).

The issue of a lack of balance in policy attention to broadband diffusion and the value of the national broadcast ecosystem is recurrent. Added to this are the broader questions of the importance of content to society, politics and culture in general and the lack of a political will to support that value fully.

\section{Terrestrial Broadcasting: DTT}

Whereas decisions at the European level (CEPT and Commission) may have stalled the allocation of resources from broadcast to broadband until 2030, this situation may not hold in the future. The Dept of Communications respondent argued 'the mobile industry is still quite powerful on a national basis in each of the member states, it certainly has the ear of the European Commission' (Dept. of Communications Respondent 2016). The current trajectory of political and economic organisation of media and the path of policymaking will signal the potential further diminution and reconfiguration of the domestic broadcasting ecology. According to the EIR respondent:

As a delivery platform, Broadcast TV will have a continued role to deliver PSB into the next decade. As countries achieve ubiquitous broadband and 
consumer consumption patterns continue to change, there may be an argument to re-assign broadcast spectrum to wireless broadband (EIR Respondent 2016).

The respondents suggested that the broader telecommunications agenda gains more attention at cabinet level and that there is a vacuum in forward-looking policy for terrestrial and domestic broadcasting.

All of the respondents propose that, in the Irish context, there is no immediate pressure on spectrum for terrestrial broadcasting, but there were mixed reactions on the possible future of the platform. There is a pressing political issue as to how to sustain a platform which is arguably at the centre of the free to air ecosystem, has a potential market of one-third of households and enables public policy surrounding media in general. The BAI respondent points to the need for possible subsidies for broadcasters using the service, as DTT is a service of general interest, and the development of new services for the platform (e.g. a film channel) which have stalled. It is essential in societal terms for socio-economic groups who cannot afford access to pay platforms, and it also provides a platform for broadcast channels that is free of the market considerations of the integrated gatekeepers such as SKY and Virgin guaranteeing carriage and access to a broadcast platform for public service media. However, the respondent argues that 'that can be a hard drum to bang in a country like Ireland where eighty-five per cent plus of carriage is on satellite and cable‘ (BAI Respondent 2016).

All of the respondents see a continued role for PS media, whether in broadcast or networked contexts. According to the Department of Communications respondent:

I think it would be the cornerstone of our policy development to try to maintain the position of public service broadcasting particularly both radio and television and in whatever way it might develop in the online space to continue to be of relevance and...to reach the level of audience it does (Dept of Communications Respondent 2016). 
The relationship between public interest regulation and terrestrial linear broadcasting is mutually re-enforcing with one justifying and enabling the other. Broadcasting is still vital to what the public/commercial and commercial/public broadcasters do in terms of revenue generation and political, and public legitimacy/engagement. The broadcasters value the free to air platform for advertising revenue generation. Broadcast content enables restructuring from a linear value chain to the networked value chain of service provision across linear and non-linear channels in an increasingly interactive and recombinant media ecosystem. The RTE respondent points to the place of broadcast media in the evolution of public service communication:

We've evolved from being a public service broadcaster to being a public service media organization...because audiences increasingly are consuming what we do all the time now on linear and non-linear platforms, but broadcasting still is very much at the centre of what we do (RTE Respondent 2016).

Undermining of terrestrial broadcasting thus potentially undermines the ongoing transition to networked public media provision. The terrestrial broadcasters all pointed to the continued centrality of their linear television and radio services in the emerging network value chain in terms of content production, demand, advertising revenue and reach. For RTE, in 2014, Online/Digital accounted for $6.8 \mathrm{~m}$ Euro in advertising revenue (9\%) compared to $80.5 \mathrm{~m}$ from Television advertising (SBP 12/6/16). Broadcast provides revenues, and, content that can be re-purposed and remediated across different platforms. It supports trust in the content that is also distributed in networked media which, as the former Minister claimed, is the value of regulation in one domain (broadcast) reaping benefits in another (networked digital media distribution). It enables presence in a crowded attention economy with crossplatform/trans-media formats anchored to linear broadcast events with high reach, visibility and inclusiveness. It is thus, arguably, an ecosystem wherein a plurality of 
media are openly navigated across platforms anchored to a public ethos of accessibility, mutuality, sociality, quality, trust \& universality. The hub of the ecosystem is free to air high shared and visible media events.

All of the respondents point to the strategic importance of free to air terrestrial public and regulated private broadcasting for the Irish audio-visual sector and its vital importance in supporting and funding production, post-production, distribution and talent development via commissioning, acquisitions, co-productions, training initiatives and funding schemes. Public service rationales provide political legitimacy for significant state investment in the sector. Both respondents from the public broadcasters point to the substantial investment in domestic content that results from their remits/funding, fuelling investment in both the independent sector, infrastructure and talent development. The BAI respondent points to the significant audio-visual capacity building and economic activity across radio and television in the public, commercial and community sector.

The EIR respondent proposed that terrestrial broadcasters need to develop multiple revenue streams, as public funding and commercial revenue are not likely to increase significantly... 'the position of small broadcasters in global markets characterised by large integrated corporations places national broadcasting under pressure. The ceding of spectrum to the mobile phone industry is a symptom of wider issues for broadcasters' (EIR Respondent 2016).

\section{Mobile Wireless Distribution}

None of the representatives accepts that the technological capacity to match broadcast television on a wireless broadband platform is imminent. The RTE Respondent suggests that the costs for citizens, broadcasters, and the existing social and geographic limits to wireless broadband diffusion make it a poor match for universal public services, but useful for networked public services that extend reach and choice. The Community Media and Commercial Television respondents emphasise attendant issues of net neutrality, data rights and platform/interface control emerging from internet- 
based service distribution. The respondent from the Independent Broadcasters of Ireland and the community media respondent point to the significant costs associated with online distribution that are not matched by diminished advertising revenues in the online context. The long-term argument about moving broadcast television onto wireless broadband or exclusively online environment is taken up by the RTE respondent:

For what political or societal purpose would you sell off a national resource that is currently being used to deliver very efficiently a television service in hi-definition to a series of private companies who are essentially going to give people the same thing using a different technology (RTE Respondent 2016).

The representative from EIR believes that only fixed line fibre could offer an alternative to terrestrial in terms of reliability and capacity. All of the respondents foresee a longer-term future wherein ubiquitous high-speed broadband could eventually be the central platform for broadcast service provision but point to the social, political-economic and technological barriers that remain. Any such future would need to ensure regulatory and commercial protections for both the medium of broadcasting and the institutional framework of public interest media.

\section{Overview}

According to the former minister, 'the reality is if the government has to do one job in the next two years it does have to answer that question, how we're going to fund broadcasters, public service broadcasters' (Ministerial Respondent 2016). The BAI respondent makes the argument that if you accept that all broadcasting serves public purposes, then some level of public funding is necessary, but 'governments are reluctant to change the current system. They're even terrified to tweak the amount of license fee for example in the public service broadcasters' (BAI Respondent 2016). 
In 2018, the then Minister initiated a policy cycle on broadcasting legislation. This may lead to much-needed legislative amendments regarding issues of funding, governance and future planning. The Minister reversed some of the cuts imposed on the public broadcaster during the phase of austerity policies and has initiated a parliamentary committee to report on the issues. The parliamentary committee has issued a report on the future of public broadcasting pointing to the funding gap that results from must carry legislation and the need to move from a Television license fee to a broadcast charge with revised means for collection and distribution of fees. An interdepartmental working group was established in 2018 to assess the possible replacement of the license fee with a broadcasting charge. Also in 2018, the government unveiled the Audio Visual Action Plan with its focus on making Ireland a hub for the global audiovisual sector. As welcome as the political attention to the Audio Visual sector might be, the Plan sidesteps the existing social, political and cultural rationales that inform the institutional framework of the broadcast sector, and it's medium based specificities.

Even if the funding mechanism is addressed, the broader question of how to sustain the ecosystem of national universal and accessible public service media (which includes digital broadcasting) and publicly regulated media persists. Arguably the values associated with public service media will eventually be supplanted without a distribution platform enabling universal access, plurality in distribution and the ability to access a platform not controlled by powerful gatekeepers that are often vertically integrated with rival media services. Addressing this will involve both European and National policy endeavors that consider public culture, media, telecoms and IT in the same space'.

\section{Conclusion}

The Irish state is managing an uneasy tension between market centric globalization/digitization, domestic socio-economic development and the retention, expansion and reimagining of institutions that are the social foundations of democratic civil society. Despite legislative support in spectrum and broadcast policy, free to air 
broadcasting, as a public interest element of the media ecosystem, is under-prioritised in the structural configuration of the state's media/communications policy. The political and economic interests surrounding spectrum underline the vulnerability of DTT as a distribution platform and highlight some of the structural issues that potentially undermine the future positioning of nationally based broadcast media within the evolving digital ecology, e.g. $5 \mathrm{G}$.

The case study above illustrates the significant institutional support for the mobile phone industries offered by Comreg and the vulnerability of terrestrial broadcasting to potential future resource grabs in 2030 and beyond. The broadcast policy community is strongly motivated to support the sector but also accept the limitations of state and politically driven support for DTT/Free to Air broadcasting. Whereas mobile broadband appears to be a poor substitute for the reach, capacity and efficiency of terrestrial broadcasting and its associated public interest dimensions of autonomy, universality and access, lack of political and policy attention to the free to air component of national communications infrastructure will potentially undermine its future claims to resources.

Alongside prolonged underfunding, there is a vacuum in communications policy relative to the potential renewal and perseverance of domestic free to air broadcasting as a strategic move in the development of new public purposes in networked digital media. Lack of political and institutional capacity to coordinate a local response to the Media-IT-Telecom ecosystem and recognise the social and cultural value of media in those contexts is observable and contrasts with the economic imperatives and power and resources dedicated to the mobile/broadband agenda. The challenges facing digital broadcasting and public media in the Irish context are eco-systemic, but regulation/governance is not.

Public policy recognises the value of the national free to air broadcasting sector, but lack of resourcing makes this an empty gesture. Some critical dynamics of the relationship of content, architecture and structure are being lost with the downgrading 
of free to air digital broadcasting that cannot be replaced or substituted merely by the provision of abundant bandwidth. Development of competition between infrastructure, network rollout and new service development as primary policy objectives is not attentive enough to how these infrastructure issues impact on the domestic production ecology for broadcasting and likewise proposed policy towards the broadcast content sectors is overly focused on a digital content services agenda.

\section{References}

Ala-Fossi M. and Lax S. (2016), 'The short future of public broadcasting: replacing digital terrestrial television with internet protocol?', The International Communications Gazette Vol 78, Issue 4.

Ala-Fossi M. and Bonet M. (2018), 'Who's Afraid of a Pan-European Spectrum Policy? The EU and the battles over the UHF broadcast band', The International Journal of Communication 12(2018), 337-358.

BAI Respondent and Murphy, K. (2016), in person interview, BAI Offices, February 2016.

British Broadcasting Corporation (BBC) (2018) BBC Distribution Policy, BBC.

Cave M. and Webb W. (2016), Spectrum Management: Using the Airwaves for Maximum Economic Benefit, Cambridge: Cambridge University Press. 
Comreg (2011), Framework Document, Dublin: Comreg.

Comreg (2014), Preliminary Consultation on the Management and use of the UHF radio frequency band in Ireland (470-790 MHZ), Dublin: Comreg 14/13.

Comreg (2018), Irish Communications Market: quarterly key data report, Dublin: Comreg.

Department of Communications Representatives and Murphy, K. (2016) in person interview, DCENR Offices, Dublin, March 2016.

Department of Communications, Energy and Natural Resources (DCENR) (2010), Spectrum Policy Statement, Dublin: DCENR.

DCENR (2014a), Report on the Future Use of UHF Spectrum for Broadcasting in Ireland, Dublin: DCENR.

DCENR (2014b), Consultation on Spectrum Policy Priorities, Dublin: DCENR.

DCENR (2014c), Responses to Consultation on Spectrum Policy Priorities, Dublin. DCENR. 
European Broadcasting Union (EBU), (2016), 'How 5G can enhance public service media's contribution to the digital society', Geneva: EBU.

European Broadcasting Union, (2017), Public Service Media Requirements in Distribution, Geneva: EBU.

EIR Respondent and Murphy, K. (2016) e-mail based interview, March 2016.

Electronic Communication Committee (2014), ECC Report on Long Term Vision for the UHF Broadcasting Band, Electronic Communication Committee.

Fischer, E. (2010) Media and New Capitalism in the Digital Age, Palgrave Macmillan.

Hesmondhalgh, D. (2012) The Cultural Industries ( $\left.3^{\text {rd }} \mathrm{Ed}\right)$, London: Sage.

Hujanen T. (2014), 'Broadcasting in the Post Broadcast era: policy, technology and content production', (Nordicom).

Humphreys, P. and Simpson, S. (2018), Regulation, Governance and Convergence in the Media, Edgar Elgar Publishing: Cheltenham.

Lamy, P. (2014), Results of the Work of the High-Level Group on the Future Use of the UHF Band (470-790 MHz), (European Commission). 
Mediatique (2017), A Report on market structure, dynamics and developments in Irish Media, Mediatique: London.

Michalis, M. (2018), 'Distribution Dilemmas for Public Service Media: evidence from the BBC', in Lowe, G, Van Den Bulck, H and Donders, K. (eds), Public Service Media in the Networked Society, Nordicom: Gothenburg.

Ministerial Respondent and Murphy, K. (2016) in person interview, respondent's office, Dublin, April 2016.

Oliver and Ohlbaum and Associates (2013), Prospects for commercial digital terrestrial television in the Republic of Ireland: A Report for the Broadcasting Authority of Ireland, Oliver and Ohlbaum Associates.

RTE Respondent and Murphy, K. (2016), in person interview, RTE, March 2016.

Simon, Jean Paul. (2016), 'Moving to Digital Media Worlds: Three Successive Transformational Waves', De Prato, G. Sanz, E. and Simon, J. (eds), Digital Media Worlds: The New Economy of Media, Palgrave Macmillan: Hampshire.

Taylor, R. (2013), 'Oil in the Ether: a critical history of spectrum auctions in Canada', Canadian Journal of Communication, Vol 38, 121-137. 
Contributor Details: Kenneth Murphy (Ph.D., Dublin City University, 2009) is a lecturer in Media and Communications at Technological University Dublin. His key research interests include media industries, media policy and media technologies. $\mathrm{He}$ can be contacted at kenneth.murphy@tud.ie

i. The interview respondents included a former Minister for Communications, a senior strategist in RTE (public broadcaster), a senior executive in UTV Ireland (commercial broadcaster), a senior executive at EIR (quadruple play telecom company), A senior and assistant civil servant in the Broadcast Policy Division at the Department of Communications, a senior executive of the Broadcasting Authority of Ireland, a senior executive of TG4 (Irish language psb), Former senior representative of the Community Radio Forum of Europe (Community TV and Radio), a senior executive from the Independent Broadcasters of Ireland (IBI). 